\title{
Non-Alcoholic Fatty Liver Disease in Africa and Middle East: An Attempt to Predict the Present and Future Implications on the Healthcare System
}

\author{
Mohamed H. Ahmed ${ }^{a,}$, , Sufian K. Noor ${ }^{b}$, Sarra O. Bushara ${ }^{b}$, Nazik Elmalaika Husain ${ }^{c}$, \\ Wadie M. Elmadhoun ${ }^{\mathrm{d}}$, Ibrahim A. Ginawi ${ }^{\mathrm{e}}$, Meissa M. Osman ${ }^{\mathrm{f}}$, \\ Abdalhafeez O. Mahmoudg, Ahmed O. Almobarak ${ }^{\text {h }}$
}

\begin{abstract}
Non-alcoholic fatty liver disease (NAFLD) encompasses a group of hepatic diseases that range in severity. NAFLD is increasingly recognized as an epidemic among different populations, including those in Africa and the Middle East. The objective of this narrative review is to document the prevalence of and risk factors for NAFLD in Africa and the Middle East and the potential implications on the healthcare systems. An in-depth search on Google Scholar, Medline and PubMed was conducted using the terms "non-alcoholic fatty liver disease" and "non-alcoholic steatohepatitis", in addition to "prevalence and risk factors for NAFLD", with special emphasis on Africa and the Middle East countries. There were three types of epidemiological studies that included prevalence, risk factors and management/complications of NAFLD. There was noticeable variation in the prevalence of NAFLD among different countries, based on the variation in the prevalence of risk factors (type 2 diabetes, obesity, metabolic syndrome and dyslipidemia) and the diagnostic tool used in the study. However, the highest prevalence rate was reported in some Middle East countries. In Africa, there were few studies about NAFLD and most reported variable prevalence rates. There is
\end{abstract}

Manuscript submitted September 27, 2017, accepted October 9, 2017

${ }^{\text {a }}$ Department of Medicine and HIV Metabolic Clinic, Milton Keynes University Hospital NHS Foundation Trust, Eaglestone, Milton Keynes, Buckinghamshire, UK

${ }^{b}$ Department of Medicine, Faculty of Medicine and Health Sciences, Nile Valley University, Atbara, Sudan

${ }^{\mathrm{c}}$ Department of Pathology, Faculty of Medicine and Health Sciences, Omdurman Islamic University, Khartoum, Sudan

${ }^{\mathrm{d}}$ Department of Pathology, Faculty of Medicine and Health Sciences, Nile Valley University, Atbara, Sudan

${ }^{\text {e}}$ College of Medicine, University of Hail, Hail, Saudi Arabia

fDepartment of Pediatric, University Hospitals of Leicester NHS Trust, Leicester, UK

gDepartment of Community Medicine, Shendi University, Shendi, Sudan

hDepartment of Pathology, Faculty of Medicine, University of Medical Sciences and Technology, Khartoum, Sudan

${ }^{i}$ Corresponding Author: Mohamed H. Ahmed, Department of Medicine and HIV Metabolic Clinic, Milton Keynes University Hospital NHS Foundation Trust, Eaglestone, Milton Keynes, Buckinghamshire, UK.

Email: elziber@yahoo.com

doi: https://doi.org/10.14740/gr913w an increasing prevalence of NAFLD as a result of the increasing risk factors, particularly in the Middle East, while in Africa, the situation is still unclear. Health providers in these regions are faced with many challenges that need urgent plans.

Keywords: Fatty liver; Africa; Lipid profile

\section{Introduction}

Non-alcoholic fatty liver disease (NAFLD) is regarded as a common and fast growing liver disease across the globe with an increase in both mortality and morbidity [1]. The estimated prevalence of NAFLD is thought to be around $25-35 \%$ across the globe and affect large different proportions of men and women. NAFLD refers to a wide spectrum of liver damage, ranging from simple steatosis to steatohepatitis, advanced fibrosis, and cirrhosis [2]. An in-depth search on Google Scholar, Medline and PubMed was conducted using the terms "non-alcoholic fatty liver disease" and "non-alcoholic steatohepatitis", in addition to "prevalence and risk factors for NAFLD", with special emphasis on "Africa" and the "Middle East" countries in names.

\section{Definition of the Terms}

NAFLD encompasses the entire spectrum of fatty liver disease in individuals without significant alcohol consumption, ranging from fatty liver to steatohepatitis and cirrhosis [3, 4].

Non-alcoholic fatty liver (NAFL) is the presence of hepatic steatosis with no evidence of hepatocellular injury in the form of ballooning of the hepatocytes or no evidence of fibrosis. The risk of progression to cirrhosis and liver failure is minimal. The definition of NAFLD requires that 1) there is evidence of hepatic steatosis, either by imaging or histology and 2) there are no causes for secondary hepatic fat accumulation such as significant alcohol consumption, use of steatogenic medication or hereditary disorders [4-9].

Non-alcoholic steatohepatitis (NASH) is the presence of hepatic steatosis and inflammation with hepatocyte injury (ballooning) with or without fibrosis. This can progress to cir- 
rhosis, liver failure and rarely lead to liver cancer [4-9]. It is a more severe form of NAFLD, and is regarded as a major cause of liver cirrhosis [4-9].

NASH cirrhosis is the presence of cirrhosis with current or previous histological evidence of steatosis or steatohepatitis [4-9].

Cryptogenic cirrhosis is the presence of cirrhosis with no obvious etiology. Patients with cryptogenic cirrhosis are likely to have two or more of the metabolic risk factors such as obesity, type 2 diabetes mellitus (T2DM), dyslipidemia and metabolic syndrome (MS).

NAFLD activity score (NAS) is an unweighted composite of steatosis, inflammation, and ballooning scores. It is a useful tool to measure changes in liver histology in patients with NAFLD in clinical trials [4-9].

MS is defined by the presence of several risk factors associated with an increased risk of cardiovascular disease (CVD); these include insulin resistance, T2DM, high blood pressure, high triglycerides (TGs), low high-density lipoprotein cholesterol (HDL-C) and an increased waist circumference (WC) (above $102 \mathrm{~cm}$ in men and $88 \mathrm{~cm}$ in women) $[3,9]$.

\section{Symptoms and Signs of NAFLD}

Most people with NAFLD have few or no symptoms. Patients may complain of fatigue, malaise, and dull right-upper-quadrant abdominal discomfort. Mild jaundice may be noticed although this is rare. More commonly NAFLD is diagnosed following abnormal liver function tests during routine blood tests. By definition, alcohol consumption of over $20 \mathrm{~g} /$ day (about 25 $\mathrm{mL} /$ day of net ethanol) excludes the condition $[3,7]$.

\section{Investigations and Diagnostic Grades}

Common findings are elevated liver enzymes and a liver ultrasound showing steatosis. An ultrasound may also be used to exclude gallstone problems (cholelithiasis). A liver biopsy is the only test widely accepted as definitively distinguishing NASH from other forms of liver disease and can be used to assess the severity of the inflammation and establish grades of liver fibrosis [3-9].

\section{Epidemiology of NAFLD}

The estimated prevalence of NAFLD is approximately $30-40 \%$ in men and $15-20 \%$ in women [7]. The prevalence of NAFLD in Italy is about $25 \%$, while the prevalence in USA is estimated to be around $33.6 \%$ and $34 \%[6,8]$. The association of NAFLD with obesity and insulin resistance is well established. The majority of individuals with NAFLD have insulin resistance and the prevalence of typ 2 diabetes among individuals with NAFLD was estimated to be around 39\% [3]. NAFLD is associated with T2DM, obesity and hyperlipidemia [4]. There is now general agreement in the literature that NAFLD is the hepatic component of the MS $[5,6]$. Importantly, diabetes is an independent risk factor for the development of NAFLD and progression to advanced liver disease, fibrosis, cirrhosis and hepatocellular carcinoma. Importantly, higher prevalence of NAFLD was recorded with diabetes. For instance, the estimated prevalence of NAFLD in people with T2DM is thought to be around $70 \%$ [7]. In UK, the estimated prevalence of NAFLD among type 2 diabetic individuals was found to be around $42.6 \%$, while in Italy the prevalence of NAFLD among type 2 diabetic individuals was around $70 \%[9,10]$. The prevalence of NAFLD among type 2 diabetic individuals in Brazil, Malaysia and China was estimated to be $42 \%, 49.6 \%$ and $61 \%$, respectively [11-13].

\section{Natural Course of NAFLD}

Once liver fibrosis develops, it carries with it ominous prognosis. For instance, in follow-up study for around three decades duration, hepatic fibrosis was regarded the strongest predictor for all-cause and disease-specific mortality in patients with histologically confirmed NAFLD [14-16]. Furthermore, in a meta-analysis, it was shown that the degree of liver fibrosis in individuals with NASH is associated with an increase in risk of liver-related mortality by almost 10 folds [15]. It was noted that there was alarming increase in the prevalence of hepatocellular carcinoma (HCC) within the last two decades. This was likely to be attributed to the increase in well-known risk factors for HCC like diabetes and obesity [17-20]. And, it is well documented in the literature that NASH is a risk factor for $\mathrm{HCC}$, even in people without cirrhosis [21-23]. Basaranoglu et al showed a proportionally greater elevation in liver transplant candidacy in patients with NAFLD and portal vein thrombosis. Their data showed that older patients were more prone to develop liver cirrhosis, HCC and a high mortality rate. While younger patients exhibited more portal vein thrombosis and gastric varices [24]. One of the difficult burdens of NAFLD on health authorities in Africa and Middle East in the near future will be the demand for liver transplant due to NAFLD. Importantly, NASH is the second leading etiology of liver disease among adults awaiting liver transplantation in the USA in the year 2013 [25]. However, NASH was the third most common indication for liver transplantation in the USA in the year 2009 $[25,26]$. Different studies showed that the frequency of NASH as the primary indication for liver transplant in USA increased from $0 \%$ or $3 \%$ to $19 \%$ or $26 \%$ within the last 13 - 15 years $[27,28]$.

In the view of the increase in prevalence of epidemic of obesity and diabetes, it is plausible to suggest that NAFLD is on a trajectory to become the most common indication for liver transplantation. Liver transplant due to NAFLD is associated with high rates of complications due to diabetes and obesity. Furthermore, the rate of recurrence of NASH was estimated to be around $20-40 \%$ [29]. NAFLD does not only cause chronic liver disease but also is regarded as multisystem disorder. For instance, NAFLD is associated with an increase in CVD mortality and twofold increase in risk of incident T2DM. Furthermore, a meta-analysis showed that NAFLD was associated with an increased risk of chronic kidney disease (CKD) [30, 
31]. Several studies showed an association between NAFLD and osteoporosis, cholesterol gallstones, colorectal cancers, sleep apnea and polycystic ovary syndrome [2, 32, 34]. Given the rising incidence and prevalence of T2DM, obesity and MS among populations in Africa and Middle East regions, it is highly recommended that policy makers should make an accurate estimate of the prevalence of NAFLD in order to predict the number of those who will develop advanced liver disease or NAFLD-related morbidities and to develop strategies for interventions to treat this condition.

This narrative review will discuss: 1) prevalence of NAFLD in adult and pediatric population in the middle East and Africa, 2) the increase in prevalence of obesity, MS and diabetes in these regions as these conditions are associated with high prevalence of NAFLD, and 3) the burden of the disease and future implications for medical forces working in these regions.

\section{Prevalence of NAFLD in Adult and Pediatric Populations in Africa and Middle East}

\section{Adult population}

The prevalence of NAFLD varies widely in different populations ranging from $4 \%$ to $47 \%$. In USA and industrialized countries, NAFLD represents the most common hepatic disorder in the current time. It affects $18 \%$ of the general adult population and $90 \%$ of markedly obese individuals with overall prevalence of $35 \%$ [35].

It is estimated that the burden of non-communicable disease will exceed that of communicable disease in the regions. For instance, it was estimated that by the year 2020 the rate of communicable disease will be $20 \%$ and non- communicable disease will increase to $60 \%$ [36]. Being the most prevalent non-communicable chronic liver disease in Western countries, NAFLD has not yet been studied in most countries in Africa and Middle East countries [37]. Furthermore, it is not easy to determine the prevalence of any health problem in areas that still lack reliable, regularly updated, population-based data. Even where data exist, poor reporting regulations and practices affect their quality and reduce the usefulness of national registries [38]. In spite of that there are some published data from some countries, but they are mostly not population-based surveys, rather they were done in certain categories of patients. In the view of the increase in the epidemic of obesity and diabetes in these regions, it is possible to predict that there will be a parallel increase in the epidemic of NAFLD.

Onyekwere et al determined the prevalence of NAFLD among patients with diabetes mellitus (DM) attending an endocrine clinic in Nigeria and compared it with non-diabetic subjects. They found that the overall prevalence of NAFLD amongst all study subjects was $8.7 \%$ and the prevalence rate of NAFLD was higher in the DM cases than in the control subjects but the difference was not statistically significant $(9.5 \%$ vs. $4.5 \%, \mathrm{P}=0.2$ ) [39]. The prevalence of NAFLD in Kuwait, Saudi Arabia, South of Iran and North of Iran was 33.3\%, $16.6 \%, 21.5 \%$ and $43.8 \%$, respectively [40, 41]. Almobarak et al studied the prevalence of NAFLD and risk factors among asymptomatic co-patients accompanying patients admitted to Gastroenterology Wards at the National Centre for GI and Liver Diseases, Ibn Sina Hospital (Khartoum, Sudan). Their study revealed $20 \%$ prevalence among the studied group with equal gender distribution and increased prevalence with age and body mass index (BMI) [42]. The prevalence of NAFLD appeared to be higher in individuals with T2DM. For instance, Almobarak et al have shown the prevalence of NAFLD among Sudanese individuals with T2DM was around 50\% [43].

Kruger et al found NAFLD in 111 out of 233 patients $(47.6 \%)$ in the Western Cape population. This high percent could be attributed to the study methods. They screened only overweight/obese subjects by ultrasound and those with fatty liver/hepatomegaly were included [37]. Zatu et al found that NAFLD in South Africa is more in women with high BMI, WC, high TG and high cholesterol [44]. Interestingly, Matsha et al showed that gamma-glutamyltransferase (GGT) is an independent risk factor for insulin resistance in African population with NAFLD [45]. Mahmoud et al have shown that serum transforming growth factor $\beta 1$ (TGF- $\beta 1$ ), MMP-1, and homoeostatic model assessment insulin resistance (HOMA-IR) proved to be potentially useful non-invasive markers in predicting fibrosis in Egyptian patients with NASH [46]. Ahmed et al showed that steatosis is a histopathologic feature in $>50 \%$ of Egyptian patients with chronic HCV infection. Insulin resistance has an important role in the pathogenesis of steatosis, which represents a significant risk factor of fibrosis together with high serum AST level and older age [47].

\section{Pediatric population}

NAFLD was reported in children and adolescent. In a crosssectional, nested case-control study, Alkassabany et al selected cases and controls randomly from outpatient schoolchildren aged 6 - 18 years attending the Radiology Clinic in Alexandria, Egypt. Their study revealed that fatty liver was prevalent in schoolchildren (15.8\%) and increased significantly with age $(\mathrm{P}=0.004)$ [48]. They found that positive family history of DM, hypertension (HTN), obesity, and liver disease were all statistically significant risk factors for fatty liver. WC and BMI were considered the best predictors of pediatric NAFLD. Furthermore, NAFLD in children was significantly associated with high TGs, low HDL-C, homoeostatic model assessment (HOMA) percentile, and the number of MS components [49]. El-Koofy et al showed that in Egyptian children polymorphisms in the promoter of microsomal triglyceride transfer protein (MTP) do exist in obese children with NASH [50]. This polymorphism leads to decreased MTP transcription, less export of TG from hepatocytes, and greater intracellular TG accumulation in liver and ultimately leads to NAFLD. Interestingly, El-Karaksy et al showed that dyslipidemia per se is a strong predictor of NAFLD among obese Egyptian children [51]. In large population study, it was estimated that the upper normal value for alanine amino transaminase (ALT) and aspartate amino transaminase (AST) was $40 \mathrm{U} / \mathrm{L}$ for the pediatric age group (10 - 18 years old). Importantly, the association with BMI was significant for ALT in both females and 
Table 1. The Prevalence of NAFLD in Some African and Middle East Countries [37, 39-43, 48]

\begin{tabular}{llll}
\hline Country & Prevalence rate (\%) & Comment(s) & Authors \\
\hline South Africa & 47.6 & Among overweight/obese subjects & Kruger et al [37] \\
Nigeria & 8.7 & Population-based & Onyekwere et al [39] \\
Kuwait & 33.3 & & Ramezani et al [40] \\
Iran & 33.9 & Meta-analysis & Sohrabpour et al [41] \\
Sudan & 20 & Among non-diabetic & Almobarak et al [42] \\
Sudan & 50 & Among diabetic patients & Almobarak et al [43] \\
Egypt & 15.8 & Among school children & Alkassabany et al [48] \\
\hline
\end{tabular}

males [52]. However, El-Koofy et al showed that in Egyptian children, there was a close association between obesity, MS, insulin resistance and NAFLD [53]. They have also concluded that ultrasound is a useful method for screening of NAFLD in children.

This review of literature is not without limitations. The search terms may have not encompassed all available literature that was published in highly visible journals and this may show why there are limited studies about NAFLD in Africa and the Middle East. Another problem is about what defines NAFLD and the use of liver biopsy to define NASH, as the diagnosis of NAFLD is not by the same tools in all studies included. A third limitation is the effect of ethnicity and economic status between different countries cannot be easily identified. It is clear that it is difficult to realize the precise prevalence of NAFLD in African and Middle East countries. This could be partially attributed to limited research work carried out concerning NAFLD prevalence, lack of population-based data and method-based diagnostic differences (Table 1) [37, 39-43, 48]. In spite of that there are some published data from some countries, but they are mostly not population-based surveys, rather they were done in certain categories of patients. However, this review is the first to shed some light on this epidemic, hopefully paving the way for further and more comprehensive work to be done in the near future.

\section{Diabetes, Obesity and MS in Africa and Middle East}

There is a very high prevalence of NAFLD in individuals with T2DM [1,9]. An ultrasonographic study of patients with T2DM showed a $42.6 \%$ prevalence of NAFLD [9]. In another study, 127 of 204 diabetic patients displayed fatty infiltration on ultrasound, and $87 \%$ of the patients with fatty infiltration who consented to biopsy had histologic confirmation of NAFLD [54]. High serum TG levels and low serum HDL levels are very common in patients with NAFLD. The prevalence of NAFLD in individuals with dyslipidemia attending lipid clinics was estimated to be $50 \%$ [55]. Basaranoglu et al showed that high carbohydrate and fructose intake may be a risk factor for development of NAFLD and progress to NASH $[56,57]$. Furthermore, Neuschwander-Tetri et al showed that dietary trans-fatty acid may also play a role in pathogenesis of NASH [58].
Up to $80 \%$ of obese people have NAFLD [59]. Obesity is a common and well-documented risk factor for NAFLD. Both excessive BMI and visceral obesity are recognized risk factors for NAFLD. In patients with severe obesity undergoing bariatric surgery, the prevalence of NAFLD can exceed $90 \%$ and up to $5 \%$ of patients may have unsuspected cirrhosis [1, 60-64]. NAFLD is associated with insulin resistance and MS (obesity, combined hyperlipidemia, T2DM, and high blood pressure) [59].

$\mathrm{DM}$ is a current challenge for most health authorities in Africa and Middle East. For instance, the prevalence of DM in Iraq was estimated to be around 9.33\% while in Kuwait it was estimated to be around $21.1 \%[65,66]$. We have shown that the prevalence of undiagnosed diabetes in rural communities of north Sudan was $2.6 \%$ and the prevalence of impaired glucose tolerance was $1.6 \%$. We identified increasing age and obesity as important risk factors [67]. Furthermore, we have also shown that in urban community in Sudan, the prevalence of diabetes is estimated to be around $19.1 \%$ [68]. This prevalence is almost similar to prevalence of diabetes in Iran (18\%) but higher than Ethiopia where the prevalence was 5.1\% [69, 70].

The Middle East and North African countries are regarded as highly prevalent countries with diabetes. For instance, in epidemiological study in 4,378 individuals in Africa and Middle East (AfME-14 countries) region, the prevalence of diabetes was shown to be $25 \%$ [71]. Importantly, several countries in these regions have diabetes prevalence of more than $18 \%$, like Kuwait (21.1\%), Lebanon (20.2\%), Qatar (20.2\%), Saudi Arabia (20.0), Bahrain (19.9\%) UAE (19.2\%) and Sudan (19.1\%) [65]. The increase in DM prevalence has been attributed to increasing urbanization, aging, obesity, reduced physical activity and unhealthy diet [65].

Type 2 diabetes accounts for over $90 \%$ of diabetes cases in Sub-Saharan Africa, whilst the other 10\% are represented by type 1 diabetes, gestational diabetes, and malnutrition-related diabetes [71]. There is strong association between type 2 diabetes and NAFLD. Therefore, it is plausible to suggest that epidemiological studies about NAFLD in these regions may reveal important outcomes for health policy makers in these regions. The other reason for the increase in NAFLD and diabetes is obesity and MS. Importantly, there is an increase in prevalence in obesity and MS in Africa and Middle East regions. Table 2 [72-115] presents studies about diabetes, MS and obesity in some African and Middle Eastern 
Table 2. The Prevalence of Diabetes, Obesity and Metabolic Syndrome in Different Countries of Middle East and Africa [72-115]

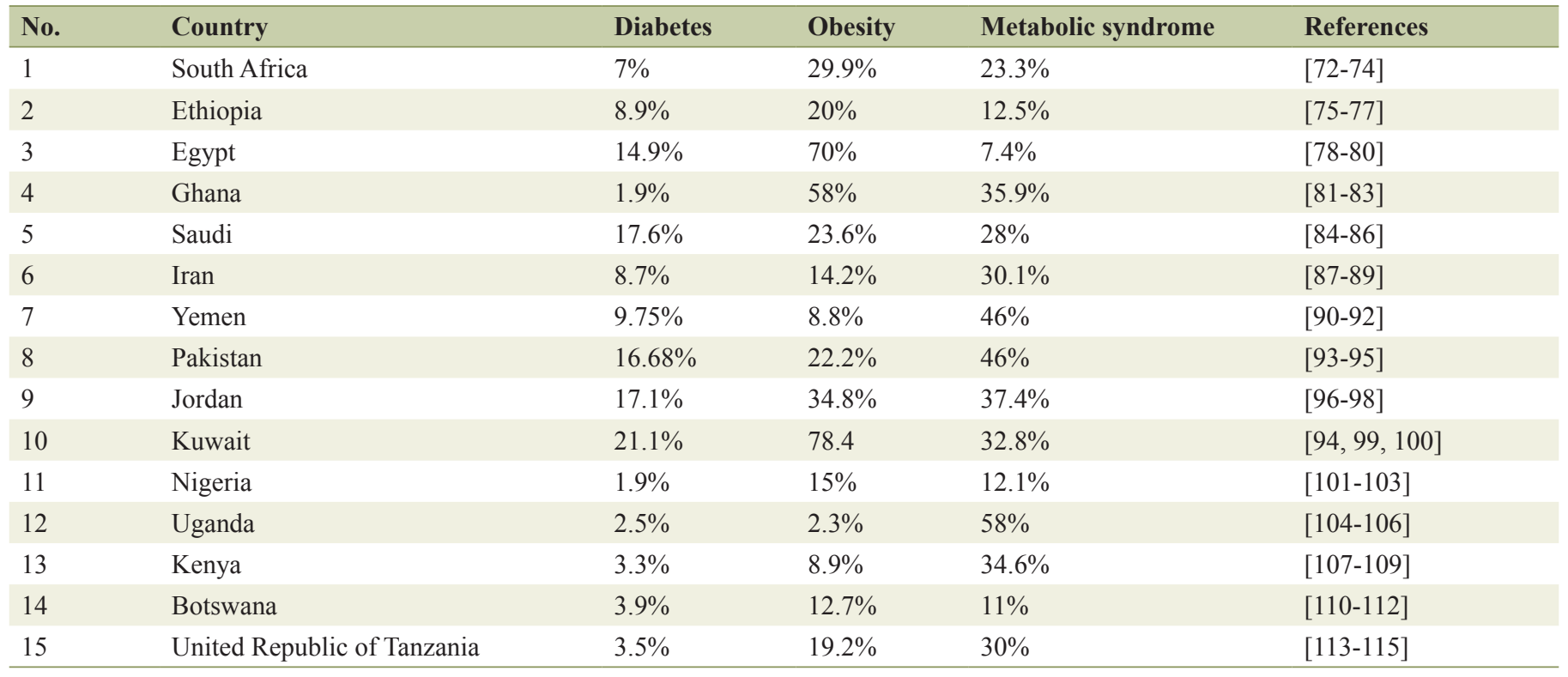

countries.

\section{Future Perspectives and Implications}

In the light of the increasing prevalence of NAFLD, necessary steps for prevention need to be taken before the epidemic of NAFLD becomes uncontainable. Given the rising incidence and prevalence of T2DM, obesity and MS among populations in Africa and Middle East regions, it is highly recommended that policy makers should make an accurate estimate of the prevalence of NAFLD in order to predict the number of those who will develop an advanced liver disease or NAFLD-related morbidities and to develop strategies for interventions to treat this condition. Liver transplant will come with huge financial cost and most countries in particular in Africa will find themselves struggling to survive such metabolic epidemic of NAFLD. The following are examples of challenges that urgently need to be addressed by the healthcare systems and healthcare workers in Africa and Middle East. 1) Despite the fact that there is a steady increase in prevalence of NAFLD, there is no cheap specific, reliable and sensitive biochemical marker to help establish diagnosis. 2) The gold standard diagnosis is through liver biopsy which is not routinely performed. However, clinical diagnosis may be based on liver ultrasound and biochemical liver function test. Still mass population screening in low-resource setting countries may not be feasible. 3) In the view of the increase in epidemic of obesity and NAFLD, financial cost may be higher for some African countries. 4) NAFLD is associated with an increased risk of developing diabetes. This may already add to the high prevalence of epidemic of diabetes and associated diabetes complications. 5) NAFLD is a multisystem disorder (CKD, CVD and chronic liver disease) and this may increase the burden of non-communicable diseases. 6) NAFLD will increase the burden on the, already limited number of, hepatologists in the region in dealing with increased numbers of individuals with liver disease such as NASH, cirrhosis and HCC. 7) NAFLD is one of the leading causes of liver transplantation. This may represent current and future challenges for most of the healthcare systems in resource-poor countries. 8) Health education for all health professions is needed, including public health specialists. This is important, as the only treatment of NAFLD is weight reduction. 9) Epidemiological studies may reveal the accurate status of the prevalence in these regions. 10) Training of more diabetiologists, hepatologists and other health care professions, e.g. dieticians, lab specialists and imaging technologists on issues related to NALFD is needed so as to increase the number of manpower to deal with this epidemic. 11) The need for scientific studies to explore the various disease aspects may add further burden to the cost of NAFLD. 12) NAFLD can be associated with HIV/AIDS. The high prevalence of HIV in Africa may raise the concern about an increase in prevalence of MS, diabetes, NAFLD and dyslipidemia. Ahmed et al suggested that the Metabolic Clinic in Milton Keynes University Hospital, UK for individuals living with HIV is currently one of the option for prevention of NAFLD [116]. Therefore, metabolic clinic in HIV centers in Africa may decrease the burden of non-communicable diseases among HIV population.

\section{Conclusion}

NAFLD will be a challenge for healthcare systems, diabetiologists and hepatologists in Africa and the Middle East. This is attributable to the remarkable increase in the epidemic of obesity and T2DM. The lack of biochemical markers and the high financial cost associated with the burden of NAFLD will be beyond the capacity of most African and Middle East countries. One particular problem extremely difficult to manage in 
the region is the need for liver transplantation. Therefore, a concentrated global initiative by all health authorities in the region is urgently needed. Furthermore, health education and public health awareness are the essence to stop the increasing prevalence of NAFLD in Africa and Middle East.

\section{References}

1. Anstee QM, Targher G, Day CP. Progression of NAFLD to diabetes mellitus, cardiovascular disease or cirrhosis. Nat Rev Gastroenterol Hepatol. 2013;10(6):330-344.

2. Ahmed MH, Barakat S, Almobarak AO. Nonalcoholic fatty liver disease and cardiovascular disease: has the time come for cardiologists to be hepatologists? J Obes. 2012;2012:483135.

3. Rocha R, Cotrim HP, Carvalho FM, Siqueira AC, Braga $\mathrm{H}$, Freitas LA. Body mass index and waist circumference in non-alcoholic fatty liver disease. J Hum Nutr Diet. 2005;18(5):365-370.

4. Hafeez S, Ahmed MH. Bariatric surgery as potential treatment for nonalcoholic fatty liver disease: a future treatment by choice or by chance? J Obes. 2013;2013:839275.

5. Kim HJ, Kim HJ, Lee KE, Kim DJ, Kim SK, Ahn CW, Lim SK, et al. Metabolic significance of nonalcoholic fatty liver disease in nonobese, nondiabetic adults. Arch Intern Med. 2004;164(19):2169-2175.

6. Bedogni G, Miglioli L, Masutti F, Tiribelli C, Marchesini G, Bellentani S. Prevalence of and risk factors for nonalcoholic fatty liver disease: the Dionysos nutrition and liver study. Hepatology. 2005;42(1):44-52.

7. Browning JD, Szczepaniak LS, Dobbins R, Nuremberg P, Horton JD, Cohen JC, Grundy SM, et al. Prevalence of hepatic steatosis in an urban population in the United States: impact of ethnicity. Hepatology. 2004;40(6):13871395.

8. Adams LA, Harmsen S, St Sauver JL, Charatcharoenwitthaya P, Enders FB, Therneau T, Angulo P. Nonalcoholic fatty liver disease increases risk of death among patients with diabetes: a community-based cohort study. Am J Gastroenterol. 2010;105(7):1567-1573.

9. Williamson RM, Price JF, Glancy S, Perry E, Nee LD, Hayes PC, Frier BM, et al. Prevalence of and risk factors for hepatic steatosis and nonalcoholic Fatty liver disease in people with type 2 diabetes: the Edinburgh Type 2 Diabetes Study. Diabetes Care. 2011;34(5):1139-1144.

10. Targher G, Bertolini L, Padovani R, Rodella S, Tessari $\mathrm{R}$, Zenari L, Day C, et al. Prevalence of nonalcoholic fatty liver disease and its association with cardiovascular disease among type 2 diabetic patients. Diabetes Care. 2007;30(5):1212-1218.

11. Chan WK, Tan AT, Vethakkan SR, Tah PC, Vijayananthan A, Goh KL. Non-alcoholic fatty liver disease in diabetics - prevalence and predictive factors in a multiracial hospital clinic population in Malaysia. J Gastroenterol Hepatol. 2013;28(8):1375-1383.

12. Lv WS, Sun RX, Gao YY, Wen JP, Pan RF, Li L, Wang J, et al. Nonalcoholic fatty liver disease and microvascular complications in type 2 diabetes. World J Gastroenterol.
2013;19(20):3134-3142.

13. Ferreira VS, Pernambuco RB, Lopes EP, Morais CN, Rodrigues MC, Arruda MJ, Silva LM, et al. Frequency and risk factors associated with non-alcoholic fatty liver disease in patients with type 2 diabetes mellitus. Arq Bras Endocrinol Metabol. 2010;54(4):362-368.

14. Blachier M, Leleu H, Peck-Radosavljevic M, Valla DC, Roudot-Thoraval F. The burden of liver disease in Europe: a review of available epidemiological data. J Hepatol. 2013;58(3):593-608.

15. Musso G, Gambino R, Cassader M, Pagano G. Metaanalysis: natural history of non-alcoholic fatty liver disease (NAFLD) and diagnostic accuracy of non-invasive tests for liver disease severity. Ann Med. 2011;43(8):617649.

16. Ekstedt M, Hagstrom H, Nasr P, Fredrikson M, Stal P, Kechagias S, Hultcrantz R. Fibrosis stage is the strongest predictor for disease-specific mortality in NAFLD after up to 33 years of follow-up. Hepatology. 2015;61(5):15471554.

17. Brunt EM. Nonalcoholic steatohepatitis. Semin Liver Dis. 2004;24(1):3-20.

18. de Marco R, Locatelli F, Zoppini G, Verlato G, Bonora E, Muggeo M. Cause-specific mortality in type 2 diabetes. The Verona Diabetes Study. Diabetes Care. 1999;22(5):756-761.

19. Konfortion J, Coupland VH, Kocher HM, Allum W, Grocock MJ, Jack RH. Time and deprivation trends in incidence of primary liver cancer subtypes in England. J Eval Clin Pract. 2014;20(4):498-504.

20. Ladep NG, Khan SA, Crossey MM, Thillainayagam AV, Taylor-Robinson SD, Toledano MB. Incidence and mortality of primary liver cancer in England and Wales: changing patterns and ethnic variations. World J Gastroenterol. 2014;20(6):1544-1553.

21. Stickel F, Hellerbrand C. Non-alcoholic fatty liver disease as a risk factor for hepatocellular carcinoma: mechanisms and implications. Gut. 2010;59(10):1303-1307.

22. Ertle J, Dechene A, Sowa JP, Penndorf V, Herzer K, Kaiser G, Schlaak JF, et al. Non-alcoholic fatty liver disease progresses to hepatocellular carcinoma in the absence of apparent cirrhosis. Int J Cancer. 2011;128(10):24362443.

23. Starley BQ, Calcagno CJ, Harrison SA. Nonalcoholic fatty liver disease and hepatocellular carcinoma: a weighty connection. Hepatology. 2010;51(5):1820-1832.

24. Basaranoglu M, Najjar SM, Demirbag AE, Senturk H. Significant cohort of non-alcoholic fatty liver disease with portal vein thrombosis in transplant waiting list. World J Hepatol. 2016;8(7):376-384.

25. Wong RJ, Aguilar M, Cheung R, Perumpail RB, Harrison SA, Younossi ZM, Ahmed A. Nonalcoholic steatohepatitis is the second leading etiology of liver disease among adults awaiting liver transplantation in the United States. Gastroenterology. 2015;148(3):547-555.

26. Charlton MR, Burns JM, Pedersen RA, Watt KD, Heimbach JK, Dierkhising RA. Frequency and outcomes of liver transplantation for nonalcoholic steatohepatitis in the United States. Gastroenterology. 2011;141(4):1249- 
1253.

27. Quillin RC, 3rd, Wilson GC, Sutton JM, Hanseman DJ, Paterno F, Cuffy MC, Paquette IM, et al. Increasing prevalence of nonalcoholic steatohepatitis as an indication for liver transplantation. Surgery. 2014;156(4):1049-1056.

28. Agopian VG, Kaldas FM, Hong JC, Whittaker M, Holt C, Rana A, Zarrinpar A, et al. Liver transplantation for nonalcoholic steatohepatitis: the new epidemic. Ann Surg. 2012;256(4):624-633.

29. Burra P, Germani G. Orthotopic liver transplantation in non-alcoholic fatty liver disease patients. Rev Recent Clin Trials. 2014;9(3):210-216.

30. Musso G, Gambino R, Tabibian JH, Ekstedt M, Kechagias S, Hamaguchi M, Hultcrantz R, et al. Association of non-alcoholic fatty liver disease with chronic kidney disease: a systematic review and meta-analysis. PLoS Med. 2014;11(7):e1001680.

31. Hamad AA, Khalil AA, Connolly V, Ahmed MH. Relationship between non-alcoholic fatty liver disease and kidney function: a communication between two organs that needs further exploration. Arab J Gastroenterol. 2012;13(4):161-165.

32. Muhidin SO, Magan AA, Osman KA, Syed S, Ahmed MH. The relationship between nonalcoholic fatty liver disease and colorectal cancer: the future challenges and outcomes of the metabolic syndrome. J Obes. 2012;2012:637538.

33. Ahmed MH, Ali A. Nonalcoholic fatty liver disease and cholesterol gallstones: which comes first? Scand J Gastroenterol. 2014;49(5):521-527.

34. Musso G, Cassader M, Olivetti C, Rosina F, Carbone G, Gambino R. Association of obstructive sleep apnoea with the presence and severity of non-alcoholic fatty liver disease. A systematic review and meta-analysis. Obes Rev. 2013;14(5):417-431.

35. Kew MC. Obesity as a cause of hepatocellular carcinoma. Ann Hepatol. 2015;14(3):299-303.

36. Akala FA, El-Saharty S. Public-health challenges in the Middle East and North Africa. Lancet. 2006;367(9515):961-964.

37. Kruger FC, Daniels C, Kidd M, Swart G, Brundyn K, Van Rensburg C, Kotze MJ. Non-alcoholic fatty liver disease (NAFLD) in the Western Cape: a descriptive analysis. S Afr Med J. 2010;100(3):168-171.

38. Maziak W. Health in the middle East. BMJ. 2006;333(7573):815-816.

39. Onyekwere CA, Ogbera AO, Balogun BO. Non-alcoholic fatty liver disease and the metabolic syndrome in an urban hospital serving an African community. Ann Hepatol. 2011;10(2):119-124.

40. Ramezani-Binabaj M, Motalebi M, Karimi-Sari H, Rezaee-Zavareh MS, Alavian SM. Are women with polycystic ovarian syndrome at a high risk of non-alcoholic Fatty liver disease; a meta-analysis. Hepat Mon. 2014;14(11):e23235.

41. Sohrabpour A, Rezvan H, Amini-Kafiabad S, Dayhim M, Merat S, Pourshams A. Prevalence of nonalcoholic steatohepatitis in Iran: a population based study. Middle East J Dig Dis. 2010;2(1):14-19.

42. Almobarak AO, Barakat $\mathrm{S}$, Khalifa $\mathrm{MH}$, Elhoweris $\mathrm{MH}$,
Elhassan TM, Ahmed MH. Non alcoholic fatty liver disease (NAFLD) in a Sudanese population: What is the prevalence and risk factors? Arab J Gastroenterol. 2014;15(1):12-15.

43. Almobarak AO, Barakat S, Suliman EA, Elmadhoun WM, Mohamed NA, Abobaker IO, Noor SK, et al. Prevalence of and predictive factors for nonalcoholic fatty liver disease in Sudanese individuals with type 2 diabetes: Is metabolic syndrome the culprit? Arab J Gastroenterol. 2015;16(2):54-58.

44. Zatu MC, van Rooyen JM, Loots du T, Greeff M, Schutte AE. A comparison of the cardiometabolic profile of black South Africans with suspected non-alcoholic fatty liver disease (NAFLD) and excessive alcohol use. Alcohol. 2015;49(2):165-172.

45. Matsha TE, Macharia M, Yako YY, Erasmus RT, Hassan MS, Kengne AP. Gamma-glutamyltransferase, insulin resistance and cardiometabolic risk profile in a middle-aged African population. Eur J Prev Cardiol. 2014;21(12):1541-1548.

46. Mahmoud AA, Bakir AS, Shabana SS. Serum TGF-beta, Serum MMP-1, and HOMA-IR as non-invasive predictors of fibrosis in Egyptian patients with NAFLD. Saudi J Gastroenterol. 2012;18(5):327-333.

47. Ahmed AM, Hassan MS, Abd-Elsayed A, Hassan H, Hasanain AF, Helmy A. Insulin resistance, steatosis, and fibrosis in Egyptian patients with chronic Hepatitis C virus infection. Saudi J Gastroenterol. 2011;17(4):245-251.

48. Alkassabany YM, Farghaly AG, El-Ghitany EM. Prevalence, risk factors, and predictors of nonalcoholic fatty liver disease among schoolchildren: a hospital-based study in Alexandria, Egypt. Arab J Gastroenterol. 2014;15(2):76-81.

49. El-Karaksy HM, El-Raziky MS, Fouad HM, Anwar GM, El-Mougy FM, El-Koofy NM, El-Hennawy AM. The value of different insulin resistance indices in assessment of non-alcoholic fatty liver disease in overweight/obese children. Diabetes Metab Syndr. 2015;9(2):114-119.

50. El-Koofy NM, El-Karaksy HM, Mandour IM, Anwar GM, El-Raziky MS, El-Hennawy AM. Genetic polymorphisms in non-alcoholic fatty liver disease in obese Egyptian children. Saudi J Gastroenterol. 2011;17(4):265-270.

51. el-Karaksy HM, el-Koofy NM, Anwar GM, el-Mougy FM, el-Hennawy A, Fahmy ME. Predictors of non-alcoholic fatty liver disease in obese and overweight Egyptian children: single center study. Saudi J Gastroenterol. 2011;17(1):40-46.

52. Kelishadi R, Abtahi SH, Qorbani M, Heshmat R, Esmaeil Motlagh M, Taslimi M, Aminaee T, et al. First national report on aminotransaminases' percentiles in children of the Middle East and North Africa (MENA): the CASPIANIII Study. Hepat Mon. 2012;12(11):e7711.

53. El-Koofy N, El-Karaksy H, El-Akel W, Helmy H, Anwar G, El-Sayed R, El-Hennawy A. Ultrasonography as a non-invasive tool for detection of nonalcoholic fatty liver disease in overweight/obese Egyptian children. Eur J Radiol. 2012;81(11):3120-3123.

54. Prashanth M, Ganesh HK, Vima MV, John M, Bandgar T, Joshi SR, Shah SR, et al. Prevalence of nonalcoholic fatty 
liver disease in patients with type 2 diabetes mellitus. J Assoc Physicians India. 2009;57:205-210.

55. Assy N, Kaita K, Mymin D, Levy C, Rosser B, Minuk G. Fatty infiltration of liver in hyperlipidemic patients. Dig Dis Sci. 2000;45(10):1929-1934.

56. Basaranoglu M, Basaranoglu G, Sabuncu T, Senturk H. Fructose as a key player in the development of fatty liver disease. World J Gastroenterol. 2013;19(8):1166-1172.

57. Neuschwander-Tetri BA, Ford DA, Acharya S, Gilkey G, Basaranoglu M, Tetri LH, Brunt EM. Dietary transfatty acid induced NASH is normalized following loss of trans-fatty acids from hepatic lipid pools. Lipids. 2012;47(10):941-950.

58. Basaranoglu M, Basaranoglu G, Bugianesi E. Carbohydrate intake and nonalcoholic fatty liver disease: fructose as a weapon of mass destruction. Hepatobiliary Surg Nutr. 2015;4(2):109-116.

59. Boza C, Riquelme A, Ibanez L, Duarte I, Norero E, Viviani P, Soza A, et al. Predictors of nonalcoholic steatohepatitis (NASH) in obese patients undergoing gastric bypass. Obes Surg. 2005;15(8):1148-1153.

60. Haentjens P, Massaad D, Reynaert H, Peeters E, Van Meerhaeghe A, Vinken S, Poppe K, et al. Identifying nonalcoholic fatty liver disease among asymptomatic overweight and obese individuals by clinical and biochemical characteristics. Acta Clin Belg. 2009;64(6):483-493.

61. Machado M, Marques-Vidal P, Cortez-Pinto H. Hepatic histology in obese patients undergoing bariatric surgery. J Hepatol. 2006;45(4):600-606.

62. Colicchio P, Tarantino G, del Genio F, Sorrentino P, Saldalamacchia G, Finelli C, Conca P, et al. Non-alcoholic fatty liver disease in young adult severely obese non-diabetic patients in South Italy. Ann Nutr Metab. 2005;49(5):289-295.

63. Beymer C, Kowdley KV, Larson A, Edmonson P, Dellinger EP, Flum DR. Prevalence and predictors of asymptomatic liver disease in patients undergoing gastric bypass surgery. Arch Surg. 2003;138(11):1240-1244.

64. Adams LA, Angulo P. Treatment of non-alcoholic fatty liver disease. Postgrad Med J. 2006;82(967):315-322.

65. Boutayeb A, Lamlili ENM, Boutayeb W, Maamri A, Ziyyat A, Ramdani N. The rise of diabetes prevalence in the Arab region. Open Journal of Epidemiology. 2012;2:5560.

66. Al Khalaf MM, Eid MM, Najjar HA, Alhajry KM, Doi SA, Thalib L. Screening for diabetes in Kuwait and evaluation of risk scores. East Mediterr Health J. 2010;16(7):725731.

67. Noor SK, Bushara SO, Sulaiman AA, Elmadhoun WM, Ahmed MH. Undiagnosed diabetes mellitus in rural communities in Sudan: prevalence and risk factors. East Mediterr Health J. 2015;21(3):164-170.

68. Elmadhoun WM, Noor SK, Ibrahim AA, Bushara SO, Ahmed MH. Prevalence of diabetes mellitus and its risk factors in urban communities of north Sudan: Populationbased study. J Diabetes. 2016;8(6):839-846.

69. Esteghamati A, Gouya MM, Abbasi M, Delavari A, Alikhani S, Alaedini F, Safaie A, et al. Prevalence of diabetes and impaired fasting glucose in the adult population of Iran: National Survey of Risk Factors for Non-Communicable Diseases of Iran. Diabetes Care. 2008;31(1):9698.

70. Abebe SM, Berhane Y, Worku A, Assefa A. Diabetes mellitus in North West Ethiopia: a community based study. BMC Public Health. 2014;14:97.

71. Alsheikh-Ali AA, Omar MI, Raal FJ, Rashed W, Hamoui $\mathrm{O}$, Kane A, Alami M, et al. Cardiovascular risk factor burden in Africa and the Middle East: the Africa Middle East Cardiovascular Epidemiological (ACE) study. PLoS One. 2014;9(8):e102830.

72. International diabetes federation/Africa (http://www.idf. org/membership/afr/south-africa) accessed 13/2/2016.

73. Julia H. Goedecke, Courtney L. Jennings, Estelle V. Lambertc - chronic diseases of lifestyle in South Africa since 1995 - 2005 (http://www.mrc.ac.za/chronic/cdlchapter7. pdf).

74. Motala AA, Esterhuizen T, Pirie FJ, Omar MA. The prevalence of metabolic syndrome and determination of the optimal waist circumference cutoff points in a rural South african community. Diabetes Care. 2011;34(4):10321037.

75. Fikru Tesfaye, Peter Byass, Stig Wall. Population based prevalence of high blood pressure among adults in Addis Ababa: uncovering a silent epidemic Biomed central. http://bmccardiovascdisord.biomedcentral.com/articles/10.1186/1471-2261-9-39.

76. Cohen MP, Stern E, Rusecki Y, Zeidler A. High prevalence of diabetes in young adult Ethiopian immigrants to Israel. Diabetes. 1988;37(6):824-828.

77. Tran A, Gelaye B, Girma B, Lemma S, Berhane Y, Bekele T, Khali A, et al. Prevalence of metabolic syndrome among working adults in ethiopia. Int J Hypertens. 2011;2011:193719.

78. International diabetes federation. http://www.idf.org/ membership/mena/egypt.

79. Egyptians are the fattest Africans, says WHO. Egypt independent. http://www.egyptindependent.com/news/ egyptians-are-fattest-africans-says-who.

80. Aboul Ella NA, Shehab DI, Ismail MA, Maksoud AA. Prevalence of metabolic syndrome and insulin resistance among Egyptian adolescents 10 to 18 years of age. J Clin Lipidol. 2010;4(3):185-195.

81. International diabetes federation. http://www.idf.org/ membership/mena/Ghana.

82. http://www.obesitycenter.edu.sa/Patients-Public/Obesityin-saudi-Arabia.aspx.

83. Gyakobo M, Amoah AG, Martey-Marbell DA, Snow RC. Prevalence of the metabolic syndrome in a rural population in Ghana. BMC Endocr Disord. 2012;12:25.

84. International diabetes federation. http://www.idf.org/ membership/mena/saudi-arabia.

85. Kumah DB, Akuffo KO, Abaka-Cann JE, Affram DE, Osae EA. Prevalence of overweight and obesity among students in the Kumasi Metropolis. J Nutr Metab. 2015;2015:613207.

86. Aljohani NJ. Metabolic syndrome: Risk factors among adults in Kingdom of Saudi Arabia. J Family Community Med. 2014;21(3):170-175. 
87. Esteghamati A, Meysamie A, Khalilzadeh O, Rashidi A, Haghazali M, Asgari F, Kamgar M, et al. Third national Surveillance of Risk Factors of Non-Communicable Diseases (SuRFNCD-2007) in Iran: methods and results on prevalence of diabetes, hypertension, obesity, central obesity, and dyslipidemia. BMC Public Health. 2009;9:167.

88. Kelishadi R, Alikhani S, Delavari A, Alaedini F, Safaie A, Hojatzadeh E. Obesity and associated lifestyle behaviours in Iran: findings from the First National Noncommunicable Disease Risk Factor Surveillance Survey. Public Health Nutr. 2008;11(3):246-251.

89. Azizi F, Salehi P, Etemadi A, Zahedi-Asl S. Prevalence of metabolic syndrome in an urban population: tehran lipid and glucose study. Diabetes Res Clin Pract. 2003;61(1):29-37.

90. Al-Sharafi BA, Gunaid AA. Prevalence of obesity in patients with type 2 diabetes mellitus in yemen. Int J Endocrinol Metab. 2014;12(2):e13633.

91. Gunaid AA. Obesity, overweight and underweight among adults in an urban community in Yemen. East Mediterr Health J. 2012;18(12):1187-1193.

92. Bamashmoos MA, Al Serouri AW. Roshde. Metabolic syndrome among obese patients attending the medical clinics of the three teaching hospitals at Sana's City, Yemen. Funct Foods Health Dis. 2011;1(6):214-221.

93. Shera AS, Basit A, Fawwad A, Hakeem R, Ahmedani MY, Hydrie MZ, Khwaja IA. Pakistan National Diabetes Survey: prevalence of glucose intolerance and associated factors in the Punjab Province of Pakistan. Prim Care Diabetes. 2010;4(2):79-83.

94. Streib, Lauren (2 August 2007). World's Fattest Countries. Forbes.Basit A.

95. Basit A, Shera AS. Prevalence of metabolic syndrome in Pakistan. Metab Syndr Relat Disord. 2008;6(3):171-175.

96. Ajlouni K, Khader YS, Batieha A, Ajlouni H, El-Khateeb M. An increase in prevalence of diabetes mellitus in Jordan over 10 years. J Diabetes Complications. 2008;22(5):317-324.

97. Alarjan JF, Hindawi OS, Judge LW, Aleyadh ZA, Bellar DM. Prevalence of obesity and behaviors associated with the development of metabolic disease among medical practitioners in Jordan. J Educ Health Promot. 2015;4:17.

98. Yasein N, Masa'd D. Metabolic syndrome in family practice in Jordan: a study of high-risk groups. East Mediterr Health J. 2011;17(12):943-948.

99. International Diabetes Federation. IDF Diabetes Atlas. 15th Edition, International Diabetes Federation, Brussels. 2011.

100. Al Zenki S, Al Omirah H, Al Hooti S, Al Hamad N, Jackson RT, Rao A, Al Jahmah N, et al. High prevalence of metabolic syndrome among Kuwaiti adults - a wake-up call for public health intervention. Int J Environ Res Public Health. 2012;9(5):1984-1996.

101. Chukwuonye, II, Chuku A, John C, Ohagwu KA, Imoh $\mathrm{ME}$, Isa SE, Ogah OS, et al. Prevalence of overweight and obesity in adult Nigerians - a systematic review. Dia- betes Metab Syndr Obes. 2013;6:43-47.

102. http://www.ncbi.nlm.nih.gov/pmc/articles/PMC3556 860/ international diabetes federation.

103. https://www.idf.org/membership/afr/nigeria.

104. Adegoke OA, Adedoyin RA, Balogun MO, Adebayo RA, Bisiriyu LA, Salawu AA. Prevalence of metabolic syndrome in a rural community in Nigeria. Metab Syndr Relat Disord. 2010;8(1):59-62.

105. International diabetes federation - http://www.idf.org/ membership/afr/uganda.

106. Baalwa J, Byarugaba BB, Kabagambe EK, Otim AM. Prevalence of overweight and obesity in young adults in Uganda. Afr Health Sci. 2010;10(4):367-373.

107. Muyanja D, Muzoora C, Muyingo A, Muyindike W, Siedner MJ. High prevalence of metabolic syndrome and cardiovascular disease risk among people with HIV on stable ART in southwestern Uganda. AIDS Patient Care STDS. 2016;30(1):4-10.

108. Tiffany L.E. Jones. Diabetes Mellitus: the increasing burden of disease in Kenya. South Sudan Medical Journal. http://www.southsudanmedicaljournal.com/archive/ august-2013/diabetes-mellitus-the-increasing-burden-ofdisease-in-kenya.html.

109. Kenya - Adult obesity prevalence, female - world data atlas - http://knoema.com/atlas/Kenya/Adult-obesityprevalence-female.

110. Kaduka LU, Kombe Y, Kenya E, Kuria E, Bore JK, Bukania ZN, Mwangi M. Prevalence of metabolic syndrome among an urban population in Kenya. Diabetes Care. 2012;35(4):887-893.

111. Botswana. Adult obesity prevalence, male. http://knoema.com/atlas/Botswana/Adult-obesity-prevalence-male.

112. Botsuana prevalence of diabetes. http://www.indexmundi.com/facts/botswana/diabetes-prevalence.

113. International diabetes federation. http://www.idf.org/ membership/afr/tanzania.

114. Grace A Shayo, Ferdinand M Mugusi. Prevalence of obesity and associated risk factors among adults in Kinondoni municipal district, Dar es Salaam Tanzania - Biomed center. http://bmcpublichealth.biomedcentral.com/articles/10.1186/1471-2458-11-365.

115. Kagaruki Gibson B, Kimaro, Godfather D, Mweya Clement N, Kilale Andrew M, Mrisho Ray M, Shao Amani F, Kalinga Akili K, Kahwa Amos M, Ngadaya Esther S, Materu Godlisten S, Mfinanga Sayoki G, Mayige Mary T, Gomez Nelida Virginia, Wang Ronald. Prevalence and risk factors of metabolic syndrome among individuals living with HIV and Receiving Antiretroviral Treatment in Tanzania - EBSCO host connection. http:/connection. ebscohost.com/c/articles/99607803/prevalence-risk-factors-metabolic-syndrome-among-individuals-living-hivreceiving-antiretroviral-treatment-tanzaniaAUTHOR.

116. Ahmed MH, Woodward C, Mital D. Metabolic clinic for individuals with HIV/AIDS: a commitment and vision to the future of HIV services. Cardiovascular Endocrinology. 2017;6:109-112. 